Communication

\title{
Investigation of Molecular Size Effect on the Formation of Lignin Nanoparticles by Nanoprecipitation
}

\author{
Jae Hoon Lee ${ }^{1}$, Shin Young Park ${ }^{1}$, In-Gyu Choi ${ }^{2}$ and Joon Weon Choi ${ }^{3, *}$ \\ 1 Department of Forest Sciences, College of Agriculture and Life Sciences, Seoul National University, \\ 599 Gwanak-ro, Gwanak-gu, Seoul 151-921, Korea; tirchonail@snu.ac.kr (J.H.L.); sypk1992@snu.ac.kr (S.Y.P.) \\ 2 Research Institute of Agriculture and Life Sciences, Seoul National University, Seoul 151-742, Korea; \\ cingyu@snu.ac.kr \\ 3 Graduate School of International Agricultural Technology, Institute of Green-Bio Science and Technology, \\ Seoul National University, Pyeongchang 232-916, Korea \\ * Correspondence: cjw@snu.ac.kr; Tel.: +82-33-339-5840; Fax: +82-33-339-5689
}

Received: 25 June 2020; Accepted: 15 July 2020; Published: 17 July 2020

\begin{abstract}
In recent years, several studies focused on the synthesis of lignin-based nanoparticle in aqueous solution and its potential applications of the drug carrier were investigated. In this study, soda lignin (SL) nanoparticles (i.d. $128-560 \mathrm{~nm}$ ) were synthesized by the nanoprecipitation process at three different concentrations $(1,2$, and $4 \mathrm{mg} / \mathrm{mL}$ THF) with various molecular sizes of soda lignin (NP-F1, NP-F2, and NP-F3) obtained from sequential solvent extraction. The average molecular weights of SL, F1, F2, F3, F4, and F5 were 3130, 1190, 2550, 3680, 5310, and 14,650, respectively. The average size of the spherical lignin nanoparticle was a minimum of $128 \mathrm{~nm}$ for NP-C1 and the size increased up to $560 \mathrm{~nm}$ with increasing concentration. Particle surface charge increased with increasing concentration from $-26 \mathrm{mV}$ for NP-C 1 to $-38 \mathrm{mV}$ for NP-C4. Contrary to expected general trends in polymeric nanoparticles, there was no remarkable change or trend with increasing lignin molecular weight since chemical structures of each lignin fraction are also remarkably different. Further studies to learn correlation between properties of lignin nanoparticle and its additional details regarding the chemical structures is needed.
\end{abstract}

Keywords: lignin; nanoparticle; sequential solvent extraction; nanoprecipitation; colloid

\section{Introduction}

Lignin is the second most abundant natural polymer, composed of three different C6C3 types of monolignols ( $\mathrm{p}$-coumaryl, coniferyl, and sinapyl alcohol) with various interunit linkages such as $\beta-\mathrm{O}-4$, $\beta-5$, and biphenyl [1]. Native lignin has complex and three-dimensional amorphous structures with a high degree of condensation, which allows the lignin to resist physical, chemical, and/or biological forces. Due to this resistance, the utilization of lignin in high value-added products is very difficult [2]. Most lignins are produced as a waste by the pulp industry (70 million tons per year), but they are also expected to be a byproduct from sugar-based biofuels and bioproducts (less than 10 million tons per year) [3,4]. However, only $2 \%$ of lignin byproducts are used as a value-added product, which traditionally has been used as a stabilizer for plastics and rubber [5,6], phenolic resins [7] and automotive brakes [8]. Production research on aromatic chemicals, carbon fibers, and thermoplastic or fusible materials from various lignins has also been performed. All of the lignin uses mentioned so far require proper conversion process conditions, but it is also important to select suitable raw lignin materials because their structural features significantly influence the yield and characteristics of the 
target products. An in-depth study of the structural features of lignin must be conducted before its widespread utilization.

A drug delivery system is generally designed to improve the pharmacological and therapeutic profile of a drug molecule inside the body of humans or animals [9]. The global drug delivery systems market was valued at 510 billion USD in 2016 and it is anticipated that the market will expand at a compound annual growth rate (CAGR) of 7\% from 2017 to 2025 to reach approximately 900 billion USD. Conventional drug delivery systems have many problems that may be potentially overcome by methods that can enhance solubility and sustained release of drugs. Nanoparticle-based drug delivery systems show promise as active vectors due to their drug-release ability. Their subcellular size allows higher intracellular uptake than other particulate systems and they can improve the stability of active drugs or other substances. Among them, the nanocapsule is a vesicular system in which a drug is confined in a space consisting of an inner liquid core encapsulated by a polymeric membrane.

Polymers used for drug encapsulation are preferably produced from natural compounds. Thus many biopolymers, such as polysaccharides, lipids, and proteins, have been studied in detail regarding application to release substances. However, studies of lignin for biomedical applications, especially for drug release, are rare. Lignin is the most abundant phenolic biopolymer in nature, with great biocompatibility. To assert the potential use of lignin capsules in biomedical fields, in vitro cytotoxicity studies of capsules were performed and positive results were achieved $[10,11]$. Meanwhile, in recent years, most nanoparticle/nanocapsule production techniques are based on the nanoprecipitation process [12]. Studies regarding various parameters that control particle size and drug loading for nanocapsules prepared by nanoprecipitation were also performed. However, few studies investigate the effect of structural characteristics of lignin, an important parameter that could explain the enormous effect on properties (particle size and encapsulation efficiency) of nanoparticles [13].

In this study, we aimed to clarify the effect of lignin molecular weight on the formation of nanoparticles and related properties. To determine the effects of molecular weight on particle size, shape, and colloidal properties, six different fractions with a remarkable molecular weight difference from lignin were obtained by sequential solvent extraction [14,15]. Lignin nanoparticles were synthesized by nanoprecipitation and recovered by centrifugation and freeze-drying. Physicochemical properties of lignin fractions and nanoparticles were analyzed, and the effects of the molecular weight of lignin on the formation of nanoparticles were determined.

\section{Materials and Methods}

\subsection{Lignin Fractionation}

Commercial soda lignin (SL) from soda pulping of mixture of wheat straw and sarkanda grass (Saccharum bengalense) was provided by Granit Research and Development SA. SL was fractionated by sequential organic solvent extraction systems (ethyl acetate, 2-butanone, methanol, acetone, and 95\% dioxane), as described in previous literature [14]. The recovered fractions were named F1, F2, F3, F4, F5, and INS (insoluble, finally undissolved fraction) and the yield of each was determined. The molecular weight and polydispersity index (PDI, molar mass averages of the weight/molar mass averages of the number) of the lignin and its fractions were analyzed using gel permeation chromatography with 1260 Infinity II Liquid Chromatography (LC) Systems (Agilent Technologies Korea Ltd., Seoul, Korea). To calculate the phenolic hydroxyl group in lignin fractions, proton NMR was performed with a Bruker AVANCE $600 \mathrm{MHz}$ instrument. Methoxyl group content in lignin fractions was measured as follows: $30 \mathrm{mg}$ lignin was dissolved in $4 \mathrm{~mL} \mathrm{HI}$ at $130{ }^{\circ} \mathrm{C}$ for $0.5 \mathrm{~h}$. The reaction was followed by the addition of $3 \mathrm{~mL}$ pentane and $200 \mu \mathrm{L}$ ethyl iodide (internal standard)/pentane (1:9 v/v). Finally, the upper phase was collected and then analyzed using a 7890A Gas Chromatography (GC) Systems (Agilent Technologies Korea Ltd., Seoul, Republic of Korea). 


\subsection{Lignin Nanoparticle Synthesis}

The SL nanoparticle formation method was modified from the Lievonen's method [16]. SL was dissolved in tetrahydrofuran (THF) at three different concentrations $(1,2$, and $4 \mathrm{mg} / \mathrm{mL})$ and product nanoparticles were designated as NP-C1, NP-C2, and NP-C4, respectively. Each fractionated SL was also dissolved in THF at a concentration of $2 \mathrm{mg} / \mathrm{mL}$. Products were labeled as NP-F1, NP-F2, NP-F3, NP-F4, and NP-F5, respectively. Lignin solutions were filtered with a $0.50-\mu \mathrm{m}$ syringe filter then inserted into a dialysis tube (dialysis tubing cellulose membrane, MW cut-off $=14,000$, Sigma-Aldrich). The tube was immersed in an excess of deionized water (replaced at intervals of $3 \mathrm{~h}$ ) for over $12 \mathrm{~h}$ with stirring at $150 \mathrm{rpm}$. After the nanoprecipitation process, nine different lignin nanoparticles were collected by centrifugation followed by freeze-drying (Figure 1).
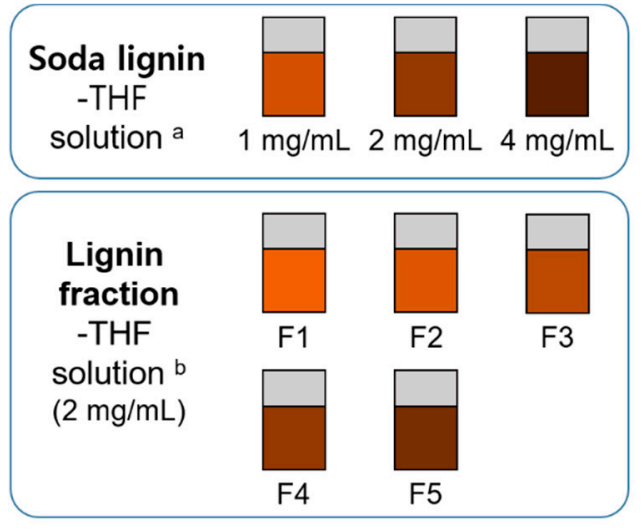
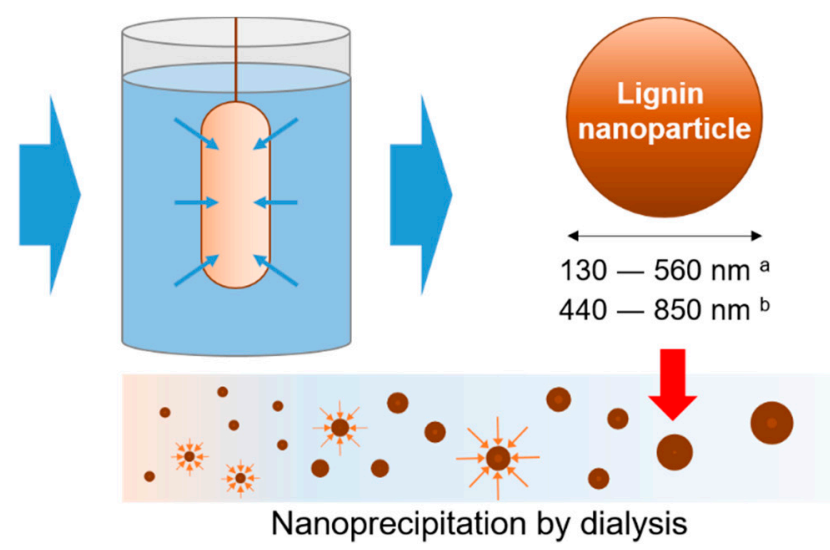

Figure 1. Schematics of the lignin nanoparticle formation.

\subsection{Analytical Methods}

Transmission electron microscopy (TEM) was used to obtain images of the lignin nanoparticles (LIBRA 120, 120 kV, Carl Zeiss, Oberkochen, Germany). Dispersions were introduced on a carbon-coated copper grid. Excess water was removed by blotting using filter paper. Size distribution from the TEM image was manually analyzed using ImageJ.

Peak size based on intensity weighted distributions, PD (square of standard deviation/square of mean diameter), and zeta potential in the colloidal dispersion were analyzed by a Zetasizer Nano ZS instrument (Malvern Instruments Ltd., Worcestershire, UK). To measure the factors, samples were diluted in deionized water (approximately $0.1 \mathrm{mg} / \mathrm{mL}$ ). Zeta potential data were obtained using the Smoluchowski equation.

\section{Results and Discussion}

\subsection{Structural Features of Lignin Fractions}

The yield, molecular weight, phenolic $\mathrm{OH}$, and methoxyl contents of each fraction from SL are shown in Table 1. SL was fractionated with five different organic solvents. Solvation properties of the solvents used in this experiment are as follows: ethyl acetate (Hildebrand solubility parameter, $\delta=9.1$, wavelength shift, $\Delta \mu=0.12)$, 2-butanone $(\delta=9.3)$, methanol $(\delta=14.3, \Delta \mu=0.28)$, acetone $(\delta=9.8$, $\Delta \mu=0.14)$, and $95 \%$ dioxane $(\delta=10.0, \Delta \mu=0.14) /$ water $(\delta=23.4, \Delta \mu$ is very high). The yields of $\mathrm{F} 1$ to F5 and INS were $30.1 \%, 25.5 \%, 24.7 \%, 2.0 \%, 11.2 \%$, and $6.5 \%$, respectively. The molecular weights of F1 to F5 were 1190, 2550, 3680, 5310, and 14,650, respectively. INS showed low solubility in the gel permeation chromatography solvent, therefore, we could not determine its molecular weight. As the fractionation step proceeded, the molecular weight of the lignin fraction increased. Several studies showed that a tacticity or increase in the solvation power contributed to an increase in the molecular weight $[17,18]$. Due to the similarity of solvation properties between methanol and acetone, the yield of 
F4 was relatively lower than that of F3. However, there was a remarkable molecular weight difference between F3 and F4 (3680 and 5310, respectively). F1 to F4 showed improve PDI values (less than 2.6) compared to that of SL (3.0), indicating that the fractions were homogenized by the sequential solvent extraction.

Table 1. Yields and molecular weight distribution.

\begin{tabular}{ccccccc}
\hline Samples & $\begin{array}{c}\text { Yield } \\
\text { (wt \%) }\end{array}$ & Mw & $\begin{array}{c}\text { Molecular Weight } \\
\text { Mn }\end{array}$ & PDI & $\begin{array}{c}\text { Phenolic OH } \\
\text { (mmol/g) }\end{array}$ & $\begin{array}{c}\text { Methoxyl } \\
\text { (mmol/g) }\end{array}$ \\
\hline SL & - & 3130 & 1030 & 3.0 & 1.8 & 3.4 \\
F1 & 30.1 & 1190 & 660 & 1.8 & 2.6 & 3.9 \\
F2 & 25.5 & 2550 & 1200 & 2.1 & 2.2 & 3.9 \\
F3 & 24.7 & 3680 & 1630 & 2.3 & 1.7 & 3.5 \\
F4 & 2.0 & 5310 & 2110 & 2.5 & 1.6 & 3.4 \\
F5 & 11.2 & 14,650 & 4700 & 3.1 & 0.8 & 3.1 \\
INS & 6.5 & - & - & - & - & 1.3 \\
\hline
\end{tabular}

The amount of phenolic $\mathrm{OH}$ groups in SL was $1.8 \mathrm{mmol} / \mathrm{g}$. Relatively low molecular weight fractions had more phenolic $\mathrm{OH}$ groups than SL (2.6 mmol/g and $2.2 \mathrm{mmol} / \mathrm{g}$ for F1 and F2). On the contrary, relatively high molecular weight fractions had fewer but similar phenolic $\mathrm{OH}$ groups $(1.7 \mathrm{mmol} / \mathrm{g}$ and $1.6 \mathrm{mmol} / \mathrm{g}$ for F3 and F4). F5 showed the lowest phenolic OH group content of all fractions, less than $1.0 \mathrm{mmol} / \mathrm{g}$. This is indirect evidence suggesting that many of phenolic hydroxyl groups in low molecular weight fractions remain free, and those high in molecular weight participate in lignin internal linkages (e.g., $\beta-\mathrm{O}-4$ and $\beta-5$ ). The methoxyl group content showed a slight decrease from $3.9 \mathrm{mmol} / \mathrm{g}$ for $\mathrm{F} 1$ to $3.1 \mathrm{mmol} / \mathrm{g}$ for F5.

Molecular weights of the lignin fractions dissolved in THF at different concentrations and molecular weights are shown in Table 2 since lignin should be dissolved in THF to make nanoparticles by nanoprecipitation. THF soluble fractions showed relatively low PDIs compared to those of raw SL under all concentrations $(2.2,2.5$, and 2.5 for $1 \mathrm{mg} / \mathrm{mL}, 2 \mathrm{mg} / \mathrm{mL}$, and $4 \mathrm{mg} / \mathrm{mL}$, respectively). Molecular weights of the THF soluble fractions were much lower than those of SL and increased with increasing concentration from 1810 to 2490 . It is suggested that accession of polymer concentration caused an increased interaction between lignin and other molecules, and thus the average molecular weight and PDI increased. On the other hand, the molecular weight of F1 to F4 did not change much when dissolved in THF. The molecular weight of F5 dissolved in THF, which showed low solubility, greatly declined because low molecular weight lignin fractions specifically dissolved in the solvent.

Table 2. Solubility and molecular weight distribution of soda lignin (SL) fractions dissolved in THF.

\begin{tabular}{ccccc}
\hline \multirow{2}{*}{ Samples } & Amount of Solute (\%) & \multicolumn{3}{c}{ Molecular Weight } \\
\cline { 3 - 5 } & & Mw & Mn & PDI \\
\hline SL & - & 3130 & 1030 & 3.0 \\
$1 \mathrm{mg} / \mathrm{mL}$ & 92.0 & 1810 & 820 & 2.2 \\
$2 \mathrm{mg} / \mathrm{mL}$ & 87.7 & 2160 & 880 & 2.5 \\
$4 \mathrm{mg} / \mathrm{mL}$ & 86.5 & 2490 & 980 & 2.5 \\
$2 \mathrm{mg} / \mathrm{mL} \mathrm{F1}$ & 100.0 & 1150 & 850 & 1.3 \\
$2 \mathrm{mg} / \mathrm{mL} \mathrm{F} 2$ & 100.0 & 2250 & 1530 & 1.5 \\
$2 \mathrm{mg} / \mathrm{mL}$ F3 & 93.0 & 3390 & 2170 & 1.6 \\
$2 \mathrm{mg} / \mathrm{mL} \mathrm{F4}$ & 94.2 & 5900 & 3630 & 1.6 \\
$2 \mathrm{mg} / \mathrm{mL}$ F5 & 45.5 & 6000 & 2290 & 2.6 \\
$2 \mathrm{mg} / \mathrm{mL}$ INS & - & - & - & - \\
\hline
\end{tabular}




\subsection{Effect of Lignin Concentration on Nanoparticle Synthesis}

\subsubsection{Particle Size and Shape}

In this study, nanoparticles were produced at different lignin concentrations by a solvent exchange between THF-SL solution and water. Table 3 shows the size and PDI of the lignin nanoparticle identified by measuring the TEM image or dynamic light scattering (DLS). It is generally known that the size of the polymeric nanoparticle is affected by several parameters such as stirring rate, polymer concentration, and polymer molecular weight [12]. When the polymer concentration increased, organic solution viscosity also increased; therefore, the diameter size of the polymeric nanoparticle became greater. The average particle size was at a minimum at $1 \mathrm{mg} / \mathrm{mL}$ concentration. The size then increased with increasing concentration, from $128 \mathrm{~nm}$ for NP-C1 to $559 \mathrm{~nm}$ for NP-C4 (peak size). It is known that the smaller particle sizes easily move in the blood vessels, yet evades phagocytosis by macrophages [19-21]. The shape of the particle also affects the margination in blood vessels, besides the margination tendency for a spherical nanoparticle depends on the size; thus demonstrating extended circulation time in the living organism $[22,23]$. The particle produced at the condition of $1 \mathrm{mg} / \mathrm{mL}$ concentration was the only sample that presented a diameter below $200 \mathrm{~nm}$. PDI of the size increased with increasing concentration, indicates that a relatively more heterogeneous size distribution of lignin nanoparticles could be obtained with higher pre-dialysis concentration of lignin. There was quite a large gap between the peak size and the size from the TEM image, assuming the particles were formed in different and varying diameters. Note that the TEM image represents only a mere fraction of the whole sample.

Table 3. SL nanoparticle sizes by pre-dialysis concentration and fractions.

\begin{tabular}{|c|c|c|c|}
\hline Samples & Size from Image $(\mathrm{nm})$ & Peak Size (nm) & PD $^{\mathrm{c}}$ \\
\hline $\mathrm{NP}-\mathrm{C} 1^{\mathrm{a}}$ & 404 & 128.4 & 0.3 \\
\hline NP-C2 & 468 & 466.7 & 1.0 \\
\hline NP-C4 & 590 & 559.7 & 1.0 \\
\hline NP-F1 $b$ & 474 & 444.8 & 0.8 \\
\hline NP-F2 & 508 & 592.9 & 1.0 \\
\hline NP-F3 & 1024 & 850.3 & 1.0 \\
\hline
\end{tabular}

a NP-C $n$ : lignin nanoparticle at a concentration $n \mathrm{mg} / \mathrm{mL},{ }^{\mathbf{b}} \mathrm{NP}-\mathrm{F} n$ : nanoparticle fraction made from lignin fraction $n),{ }^{\mathrm{c}}$ (square of peak size standard deviation)/(square of peak size mean diameter).

The diameter and structure of lignin nanoparticles were observed by TEM imaging (Figure 2A-C). It is presumed that exchanging THF and water in this method involves the nanoprecipitation process [24]. Supersaturation occurs when the solvent and non-solvent are mixed and solubility of the solute decreased. Then the changes in the concentration lead to the nucleation process followed by growth by condensation of particles. We could observe the particles by TEM image that clearly shows uniformly spherical lignin nanoparticle formation with nanoprecipitation of SL. THF is much less polar than water (relative polarity 0.207), which makes it a good solvent for the solvent exchange process with water [25]. Rapid solvent exchange using THF and a dialysis tube produces the symmetric lignin nanoparticle. 

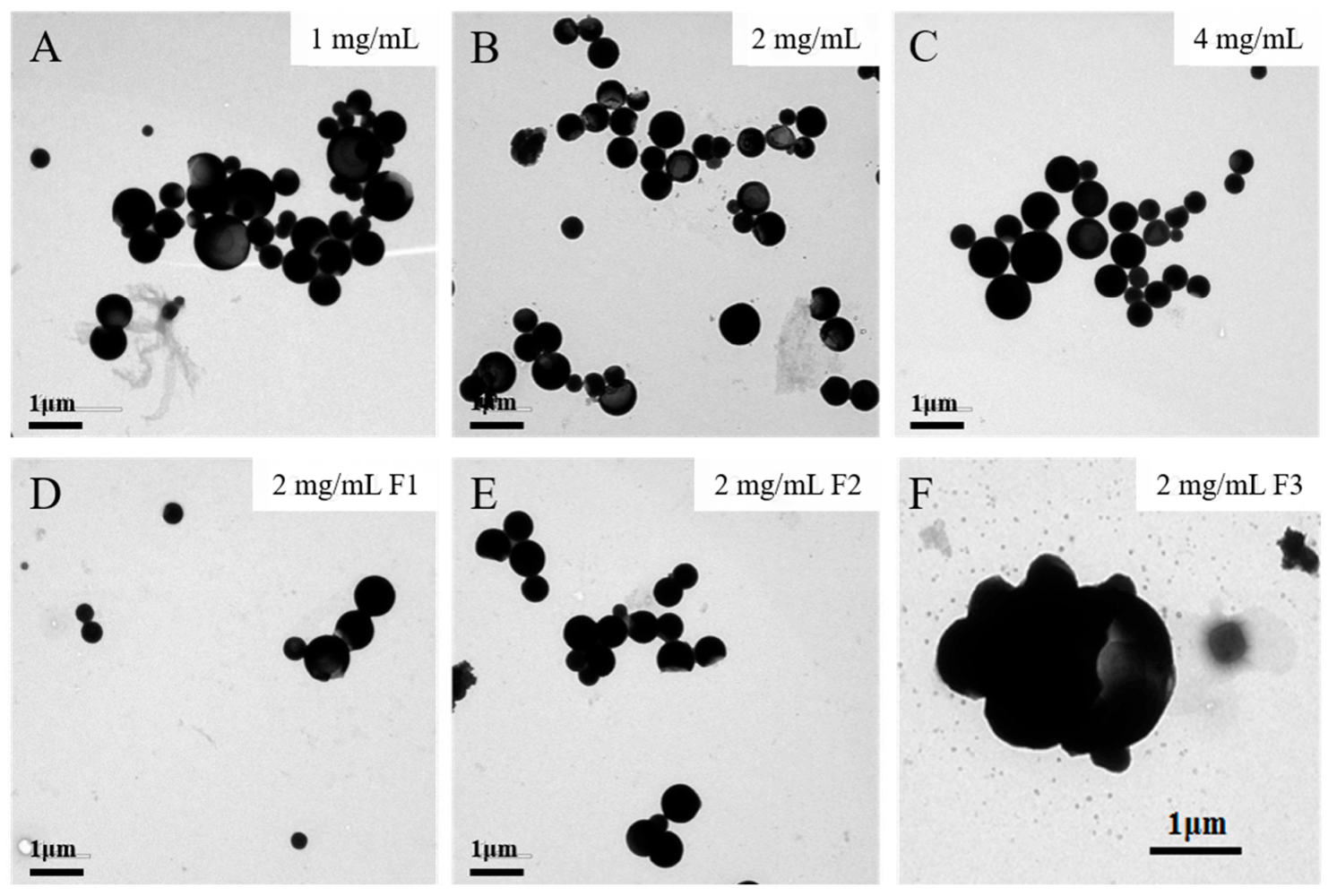

Figure 2. TEM images of (A) NP-C1, (B) NP-C2, (C) NP-C4, (D) NP-F1, (E) NP-F2, and (F) NP-F3 (NP-Cn: lignin nanoparticle at a concentration $n \mathrm{mg} / \mathrm{mL}, \mathrm{NP}-\mathrm{F} n$ : nanoparticles formed by lignin fraction $n)$.

\subsubsection{Surface Charge}

Figure $2 \mathrm{~A}-\mathrm{C}$ shows that there were some aggregates of nanoparticles in a colloidal liquid. It can generally be explained that attractive interactions between condensates (SL nanoparticles) were stronger than repulsive interactions. Calculations using a Zetasizer gave more detailed values regarding the degree of electrostatic repulsion of SL nanoparticles. Figure 3A shows the stability of a lignin nanoparticle surface charge that was prepared at 1, 2, and $4 \mathrm{mg} / \mathrm{mL}$. Zeta potential of the nanoparticle surface increased with increasing pre-dialysis concentration, from $-26.3 \mathrm{mV}$ for $1 \mathrm{mg} / \mathrm{mL}$ to $-37.8 \mathrm{mV}$. Particle stability was achieved when the zeta potential value was more than $30 \mathrm{mV}$ or less than $-30 \mathrm{mV}$. SL nanoparticles prepared at 2 and $4 \mathrm{mg} / \mathrm{mL}$ were relatively low, under $-30 \mathrm{mV}$, and had a stable zeta potential. Under this circumstance, the colloid will resist aggregation. Further study is necessary to determine the effect of time on particle stability.

A

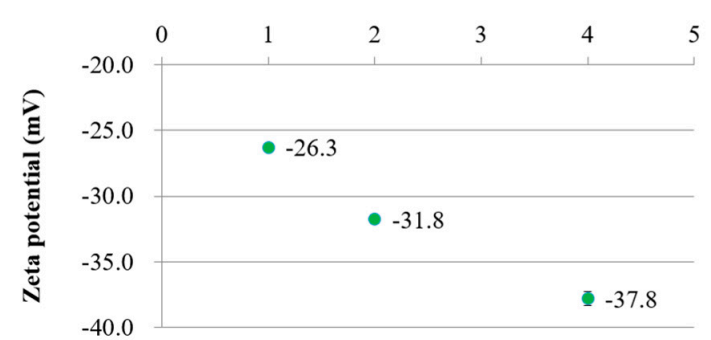

B Soda lignin fractions

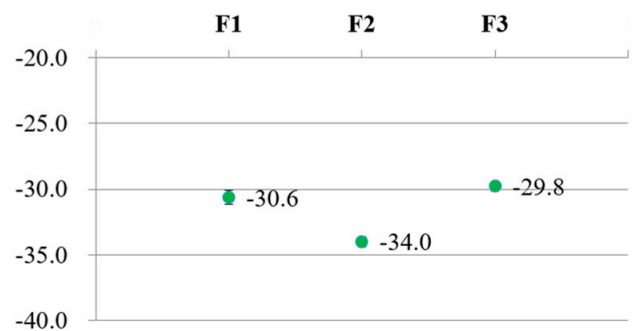

Figure 3. Zeta potential value of SL nanoparticles under different concentrations (A) and nanoparticles formed by each SL fractions (B). 


\subsection{Effect of Fractionation on Lignin Nanoparticle Synthesis}

\subsubsection{Particle Size and Shape}

The SL nanoparticles were produced at a fixed concentration $(2 \mathrm{mg} / \mathrm{mL})$, which produced more stable nanoparticle colloids than lower concentration, and different solvent-extracted fractions (F1, F2, F3, and F4). We did not perform the nanoparticle synthesis experiment with F5 due to its low solubility in THF. Table 3 shows the diameter and PDI of the nanoparticles formed by different molecular weight fractions. Generally, the higher molecular weight component, the larger the polymeric nanoparticle size can be observed. F1 and F2 show lower molecular weights than the raw material, but there was no trend of decreasing particle size in this study. The average particle size was very similar between NP-C2 and NP-F1 (468 nm and $474 \mathrm{~nm}$ in peak size, respectively). In the case of NP-F2 and NP-F3, the size increased with further fractionation processing. At all conditions, the PDI value exceeded 0.5, which indicates an unstable and heterogeneous distribution of lignin nanoparticle sizes was obtained. To produce a stable size distribution vigorous stirring is recommended rather than slow stirring [12]. Thus, we concluded that the adjustment of the stirring rate was needed in our future study.

The diameter and structure of lignin fraction nanoparticles were observed by TEM imaging (Figure 2D-F). NP-F1 (Figure 2D) and NP-F2 (Figure 2E) showed a symmetric structure, whereas NP-F3 (Figure 2F) and NP-F4 (data not shown) showed an asymmetric and partially broken shape. A hypothesis is proposed in which the structural differences between raw lignin and its fractions are the cause of the particle asymmetry. Several studies reported the differences in functional groups, elemental composition, and thermal properties between fractionated lignins [14,15]. Unfortunately, SL, F3, and F4 had similar amounts of phenolic $\mathrm{OH}$ and methoxyl groups (Table 1). Even the molecular weights of each sample show no significant difference. Therefore, it is difficult to explain the collapsed particle shape of NP-F3 and NP-F4 with the functional group difference. It is also reported that the diffusion coefficient, which represents water miscibility and polymer solubility of solvent, is affected by the polymer functional group [26]. Further studies of functional group and molecular linkage of lignin fractions are needed to determine the structural asymmetry of large molecular weight fraction nanoparticles.

\subsubsection{Colloidal Properties}

Figure 3B shows the stability of a lignin nanoparticle surface charge of NP-F1 to NP-F3. There was no trend observed in the zeta potentials of nanoparticle surfaces between the fractions. The Zeta potential of NP-F1 was $-30.6 \mathrm{mV}$. The potential was at a minimum with F2 $(-34.0 \mathrm{mV})$ and a maximum with F3 $(-29.8 \mathrm{mV})$. NP-F1 and NP-F2 showed under $-30 \mathrm{mV}$ and stable zeta potential.

\section{Conclusions}

In this study, fractionation of SL by sequential solvent extraction was carried out to obtain lignin fractions with remarkable molecular weight differences, and lignin nanoparticles were produced by nanoprecipitation with the fractions at three different concentrations. The average particle size and surface charge increased with increasing pre-dialysis concentration. The average particle size was very similar between NP-C2 and NP-F1, and increased with further fractionation. Generally, polymeric nanoparticle size increases with increasing molecular weight and amount. However, nanoparticle size increased by increasing SL concentration, and there was also a small change in particle size with increasing molecular weight. These results do not follow the general trend in polymeric nanoparticle formation since raw lignin (SL) and derived fractions have different internal linkage styles, functional group ratio, and amount compared to plastics or several synthetic biopolymers. Further studies are in progress to learn additional details regarding the chemical structures and diffusion coefficients that affect nanoparticle formation of the fractions. In future, these nanoparticles could be used as reinforcement, surfactant, and UV block, or in material delivery system such as pesticide, antioxidant, and anticancer carrier. 
Author Contributions: Conceptualization, J.W.C.; data curation, J.H.L.; methodology, J.H.L. and S.Y.P.; writing-original draft preparation, J.H.L.; writing—review and editing, I.-G.C. and J.W.C.; supervision, J.W.C. All authors have read and agreed to the published version of the manuscript.

Funding: This research was funded by the Basic Science Research Program (NRF-2019R1A2C2086328) of the National Research Foundation funded by the Ministry of Science and ICT.

Conflicts of Interest: The authors declare no conflict of interest.

\section{References}

1. Gillet, S.; Aguedo, M.; Petitjean, L.; Morais, A.R.C.; da Costa Lopes, A.M.; Łukasik, R.M.; Anastas, P.T. Lignin transformations for high value applications: Towards targeted modifications using green chemistry. Green Chem. 2017, 19, 4200-4233. [CrossRef]

2. Martínez, Á.T.; Speranza, M.; Ruiz-Dueñas, F.J.; Ferreira, P.; Camarero, S.; Guillén, F.; Martínez, M.J.; Gutiérrez Suárez, A.; Río Andrade, J.C.d. Biodegradation of lignocellulosics: Microbial, chemical, and enzymatic aspects of the fungal attack of lignin. Int. Microbiol. 2005, 8, 195-204.

3. Fang, Z.; Smith, R.L., Jr. Production of Biofuels and Chemicals from Lignin; Springer: Berlin, Germany, 2016.

4. Ragauskas, A.J.; Beckham, G.T.; Biddy, M.J.; Chandra, R.; Chen, F.; Davis, M.F.; Davison, B.H.; Dixon, R.A.; Gilna, P.; Keller, M.; et al. Lignin valorization: Improving lignin processing in the biorefinery. Science 2014, 344, 1246843. [CrossRef]

5. Gregorová, A.; Cibulková, Z.; Košíková, B.; Šimon, P. Stabilization effect of lignin in polypropylene and recycled polypropylene. Polym. Degrad. Stab. 2005, 89, 553-558. [CrossRef]

6. Jiang, C.; He, H.; Jiang, H.; Ma, L.; Jia, D. Nano-lignin filled natural rubber composites: Preparation and characterization. Express Polym. Lett. 2013, 7, 480-493. [CrossRef]

7. Sarkar, S.; Adhikari, B. Lignin-modified phenolic resin: Synthesis optimization. adhesive strength, and thermal stability. J. Adhes. Sci. Technol. 2000, 14, 1179-1193. [CrossRef]

8. Park, J.; Hwang, H.; Kim, J.Y.; Choi, J.W. Applicability of lignin polymers for automobile brake pads as binder and filler materials and their performance characteristics. Environ Technol 2020, 41, 488-497. [CrossRef]

9. Bianco, A.; Kostarelos, K.; Prato, M. Applications of carbon nanotubes in drug delivery. Curr. Opin. Chem. Biol. 2005, 9, 674-679. [CrossRef]

10. Tortora, M.; Cavalieri, F.; Mosesso, P.; Ciaffardini, F.; Melone, F.; Crestini, C. Ultrasound Driven Assembly of Lignin into Microcapsules for Storage and Delivery of Hydrophobic Molecules. Biomacromolecules 2014, 15, 1634-1643. [CrossRef] [PubMed]

11. Figueiredo, P.; Lintinen, K.; Kiriazis, A.; Hynninen, V.; Liu, Z.; Bauleth-Ramos, T.; Rahikkala, A.; Correia, A.; Kohout, T.; Sarmento, B.; et al. In vitro evaluation of biodegradable lignin-based nanoparticles for drug delivery and enhanced antiproliferation effect in cancer cells. Biomaterials 2017, 121, 97-108. [CrossRef]

12. Martinez Rivas, C.J.; Tarhini, M.; Badri, W.; Miladi, K.; Greige-Gerges, H.; Nazari, Q.A.; Galindo Rodriguez, S.A.; Roman, R.A.; Fessi, H.; Elaissari, A. Nanoprecipitation process: From encapsulation to drug delivery. Int. J. Pharm. 2017, 532, 66-81. [CrossRef] [PubMed]

13. Wilczewska, A.Z.; Niemirowicz, K.; Markiewicz, K.H.; Car, H. Nanoparticles as drug delivery systems. Pharmacol. Rep. 2012, 64, 1020-1037. [CrossRef]

14. Park, S.Y.; Kim, J.Y.; Youn, H.J.; Choi, J.W. Fractionation of lignin macromolecules by sequential organic solvents systems and their characterization for further valuable applications. Int J Biol Macromol 2018, 106, 793-802. [CrossRef] [PubMed]

15. Kim, J.-Y.; Park, S.Y.; Lee, J.H.; Choi, I.-G.; Choi, J.W. Sequential solvent fractionation of lignin for selective production of monoaromatics by Ru catalyzed ethanolysis. Rsc. Adv. 2017, 7, 53117-53125. [CrossRef]

16. Lievonen, M.; Valle-Delgado, J.J.; Mattinen, M.-L.; Hult, E.-L.; Lintinen, K.; Kostiainen, M.A.; Paananen, A.; Szilvay, G.R.; Setälä, H.; Österberg, M. A simple process for lignin nanoparticle preparation. Green Chem. 2016, 18, 1416-1422. [CrossRef]

17. Sun, R.; Tomkinson, J.; Jones, G.L. Fractional characterization of ash-AQ lignin by successive extraction with organic solvents from oil palm EFB fibre. Polym. Degrad. Stab. 2000, 68, 111-119. [CrossRef]

18. Kawamura, H.; Hayashi, T.; Inoue, Y.; Chujo, R. Molecular weight and tacticity fractionations in successive extraction of highly isotactic polypropylene with n-alkane solvents. Macromolecule 1989, 22, 2181-2186. [CrossRef] 
19. Gref, R.; Domb, A.; Quellec, P.; Blunk, T.; Müller, R.; Verbavatz, J.-M.; Langer, R. The controlled intravenous delivery of drugs using PEG-coated sterically stabilized nanospheres. Adv. Drug Deliv. Rev. 1995, 16, $215-233$. [CrossRef]

20. Moghimi, S.M.; Hedeman, H.; Muir, I.; Illum, L.; Davis, S.S. An investigation of the filtration capacity and the fate of large filtered sterically-stabilized microspheres in rat spleen. Biochim. Et Biophys. Acta (Bba)-Gen. Subj. 1993, 1157, 233-240. [CrossRef]

21. Devine, D.V.; Wong, K.; Serrano, K.; Chonn, A.; Cullis, P.R. Liposome-Complement interactions in rat serum: Implications for liposome survival studies. Biochim. Et Biophys. Acta (Bba) Biomembr. 1994, 1191, 43-51. [CrossRef]

22. Albanese, A.; Tang, P.S.; Chan, W.C. The effect of nanoparticle size. shape, and surface chemistry on biological systems. Annu. Rev. Biomed. Eng. 2012, 14, 1-16. [CrossRef] [PubMed]

23. Toy, R.; Peiris, P.M.; Ghaghada, K.B.; Karathanasis, E. Shaping cancer nanomedicine: The effect of particle shape on the in vivo journey of nanoparticles. Nanomedicine 2014, 9, 121-134. [CrossRef] [PubMed]

24. Miladi, K.; Sfar, S.; Fessi, H.; Elaissari, A. Nanoprecipitation process: From particle preparation to in vivo applications. In Polymer Nanoparticles for Nanomedicines; Springer: Berlin, Germany, 2016; pp. 17-53.

25. Reichardt, C.; Welton, T. Solvents and Solvent Effects in Organic Chemistry; John Wiley \& Sons: Hoboken, NJ, USA, 2011.

26. Morris, K.F.; Cutak, B.J.; Dixon, A.M.; Larive, C.K. Analysis of diffusion coefficient distributions in humic and fulvic acids by means of diffusion ordered NMR spectroscopy. Anal. Chem. 1999, 71, 5315-5321. [CrossRef] [PubMed]

(C) 2020 by the authors. Licensee MDPI, Basel, Switzerland. This article is an open access article distributed under the terms and conditions of the Creative Commons Attribution (CC BY) license (http://creativecommons.org/licenses/by/4.0/). 